\title{
L-thyroxine-induced hyperthyroidism affects elements and zinc in rats
}

\author{
Baltaci $\mathrm{AK}^{1}$, Mogulkoc $\mathrm{R}^{1}$, Belviranli $\mathrm{M}^{2}$ \\ Selcuk University, Selcuklu Medical School Department of Physiology, Konya, Turkey. \\ rasimmogulkoc@yahoo.com
}

\begin{abstract}
There is a significant relation between thyroid hormones and zinc. The establishment of low blood zinc levels in hypothyroidism as opposed to high blood zinc levels in hyperthyroidism testifies to this relation. The present study aims to examine the changes in levels of some elements in sera of rats with induced hyperthyroidism as well as the relation between these changes and zinc.

Thirty adult male rats of Sprague-Dawley type were equally allocated to three groups, particularly Group 1: General Control, Group 2: Sham-hyperthyroidism Group, and Group 3: Hyperthyroidism Group. Subsequent to decapitating the animals, their blood samples were taken and analyzed with the help of atomic emission spectrophotometer in terms of serum levels of zinc, selenium, calcium, magnesium, phosphorus, chromium, copper and iron. The levels of zinc, selenium and calcium were higher $(p<0.01)$, while those of chromium, copper, iron and phosphorus were lower $(p<0.01)$ in Group 3, relative to groups 1 and 2. These parameters were not different in groups 1 and 2 .

The results obtained from the study indicate that hyperthyroidism brings about some changes in the levels of some elements in rats. These changes might be associated with the elevation of zinc levels in hyperthyroidism (Tab. 2, Ref. 41). Full Text in PDF www.elis.sk.

Key words: hyperthyroidism, zinc, selenium, trace elements, rat.
\end{abstract}

There is a significant relation between thyroid hormones and trace elements (1). Not only are trace elements involved in thyroid hormone metabolism, but their levels in blood and tissues can be altered also by impairments in thyroid function $(1,2)$. One of the major roles of trace elements played in thyroid hormone metabolism is that of zinc (3). In both experimental animals and humans, zinc is known to affect the plasma levels of thyroid hormone and take part in thyroid activity (3). Among the endocrine functions associated with zinc are the changes observed in thyroid hormone metabolism and energy consumption of humans and animals on diet low in zinc (4). Both animal experiments and human studies demonstrate that when zinc deficiency is present alongside iodine deficiency, it can be a stimulus for goiter. However, there is no consensus on the results $(5,6)$. Morley et al $(6)$ reported that $T_{3}$ concentrations were lower in patients with chronic hepatitis and gastrointestinal ailments, as well as in those with hypozincemia, and that $\mathrm{T}_{3}$ levels could not be elevated despite zinc supplementation. It is known that erythrocyte carbonic anhydrase enzyme, and B-isozyme in particular, declines in hyperthyroid patients. Since

${ }^{1}$ Selcuk University, Selcuklu Medical School Department of Physiology, Konya, Turkey, and ${ }^{2}$ Selcuk University, Meram Medical School Department of Physiology, Konya, Turkey

Address for correspondence: R. Mogulkoc, Dr, Selcuk University, Selcuklu Medical School, Department of Physiology, 42031, Konya, Turkey. Acknowledgement: This study was supported in part by SUBAPK (Scientific Research Project Coordinator of Selcuk University). Project number is TF 2002-086. most of the zinc within erythrocytes is found in form of the metal of carbonic anhydrase, and as the thyroid hormone inhibits the synthesis of erythrocyte carbonic anhydrase B-isozyme, the concentration of intra-erythrocyte zinc is expected to display a parallel decline (7). It was reported that although intra-erythrocyte zinc levels decreased by $54 \%$ in rats with induced hyperthyroidism, there was no significant change in plasma zinc levels (8). In contrast, Simsek et al (9) found high erythrocyte zinc levels but could determine no change in plasma zinc levels in hyperthyroidism. The results reported by authors $(8,9)$ cited above seem inconsistent with the studies arguing that the plasma zinc levels increased in hyperthyroidism $(10,11)$. The studies exploring the relationship between hyperthyroidism and zinc show that the consensus has yet to be reached on this topic. The aim of the present study is to examine the changes in serum levels of some elements and their relation to zinc in rats with induced hyperthyroidism.

\section{Materials and methods}

This study was carried out at the Experimental Medicine Research and Application Center of Selcuk University (SUDAM) on the rats supplied thence. The study included 30 adult male rats of Sprague-Dawley type, 190-230 g in weight, allocated to three groups in equal numbers as follows:

Group 1: General Control Group $(\mathrm{n}=10)$; control group without any intervention.

Group 2: Sham-Hyperthyroidism Group $(\mathrm{n}=10)$; group with $0.3 \mathrm{mg} / \mathrm{kg}$ intraperitoneal serum physiologic for three weeks. 
Group 3: Hyperthyroidism Group $(\mathrm{n}=10)$; group where hyperthyroidism was induced by supplementing $0.3 \mathrm{mg} / \mathrm{kg}$ intraperitoneal L-thyroxin for three weeks.

At the end of the experimental part of the study, serum samples were collected from decapitated animals to analyze the levels of zinc, selenium, calcium, magnesium, phosphorus, chromium, copper and iron. The analyses of parameters were carried out using an inductively coupled plasma emission spectrophotometry (ICPAES; Varian Australia Pty LTD, Australia) atomic emission apparatus found in the Soil Department of Selcuk University Faculty of Agriculture. The results were expressed as mg/L.

\section{Statistics}

Computer software package was used in the statistical evaluation of findings. Arithmetic means and standard errors of all parameters were calculated. Variance analysis was used to determine the differences between groups. Least Significant Difference (LSD) Test was employed to compare group means in the variance analysis results which were statistically significant. The differences for which $\mathrm{p}<0.01$ were accepted significant.

\section{Results}

Group 3 had higher calcium, selenium and zinc $(\mathrm{p}<0.01)$ (Tab. 1 ), and lower chromium, copper, iron and phosphorus levels ( $p$ $<0.01$ ) (Tab. 2) than groups 1 and 2 . The parameters in groups 1 and 2 did not differ (Tabs 1-2).

\section{Discussion}

In the study, the highest serum zinc levels were obtained in the hyperthyroidism group (group 3). The studies about the mechanism of how blood zinc levels are affected in hyperthyroidism have produced contradictory results. Although there are reports arguing that plasma zinc levels remain unchanged in hyperthyroidism, $(8,9)$ some studies have reported significant increases in plasma zinc levels in hyperthyroidism $(11,11)$. However, many studies point out a relation between zinc defect and thyroid hormone levels $(12,13)$. Zinc is an indispensable element in the functioning of 1,5-deiodinase, which is an enzyme catalyzing the conversion of $\mathrm{T}_{4}$ into its active form $\mathrm{T}_{3}$ (14) Zinc is required not only for the activity of thyroid hormones but also for the synthesis of TSH in the anterior hypophysis and that of TRH in the hypothalamus $(15,16)$. When evaluating the current information on the relation between zinc and thyroid as a whole, any change in thyroid activity can be expected to be resulting in a change in zinc levels. According to the report by Pawan et al (17) the hyperthyroid rats increase their intestinal and renal uptake of zinc and thus have higher zinc levels in comparison to controls. It is accepted that the main reason for this event is the positive correlation between Zip 10, a zinc-carrying protein, and thyroid hormones in the intestines and kidneys (17). The high plasma zinc levels we obtained in hyperthyroid rats in our study are in concordance with reports of the researchers cited above.

Selenium levels in the hyperthyroidism group (group 3) were higher than those in other groups in our study. Selenium, a very important micronutrient in metabolism, accumulates as selenocysteine in the active part of the wide domain of proteins. Among the major selenoproteins are the iodothyronine deiodinases. These enzymes catalyze the conversion of $\mathrm{T}_{3}$ into 3 ' diiodothyronine and that of pro-hormone thyroxin $\left(\mathrm{T}_{4}\right)$ into active thyroid hormone 3,3 '5 triiodothyronine (18). The full functioning of thyroid hormones depends on the conversion of thyroxin into triiodothyronine (T3). Most $\mathrm{T}_{3}$ is produced by peripheral deionization of $\mathrm{T}_{4}$, which is catalyzed by seleno-enzyme iodothyronine 5' deiodinase. As a result, selenium is highly important in the modulation of regulatory role that the thyroid hormones play in metabolism (19). It has been noted that the changes in thyroid hormone activity lead to significant changes in selenium levels (20), as well as that the selenium deficiency puts the regulatory functions of thyroid hormones at risk (21). It was reported that selenium and zinc concentrations were significantly reduced in the thyroid tissues of patients with thyroid cancer and that these elements might have played a role in the carcinogenic process (22). Kralik et al (5) stated in their study that selenium and zinc were substantial for thyroid hormone metabolism, and that the thyroid activity could be unfavorably affected in case of deficiency in these elements. Serum selenium concentrations in hyperthyroid patients were reported to be higher than those in both healthy individuals and goiter patients (23). The high selenium levels we obtained in the hyperthyroidism group in our study seem consistent with

Tab. 1. Serum calcium, selenium, zinc and magnesium levels in study groups (mg/L).

\begin{tabular}{lcccc}
\hline Groups $(\mathrm{n}=10)$ & Calcium & Selenium & Zinc & Magnesium \\
\hline 1-Control & $195.00 \pm 11.55 \mathrm{~B}$ & $2.71 \pm 0.25 \mathrm{~B}$ & $3.75 \pm 0.40 \mathrm{~B}$ & $46.50 \pm 9.57$ \\
2-Sham- hyperthyroidism & $190.25 \pm 11.15 \mathrm{~B}$ & $2.82 \pm 0.25 \mathrm{~B}$ & $3.70 \pm 0.50 \mathrm{~B}$ & $48.80 \pm 9.35$ \\
3-hyperthyroidism & $229.45 \pm 13.40 \mathrm{~A}$ & $3.79 \pm 0.60 \mathrm{~A}$ & $5.28 \pm 0.55 \mathrm{~A}$ & $47.93 \pm 10.25$ \\
\hline
\end{tabular}

*The difference between means with different superscripted letters in the same column is statistically significant $(\mathrm{p}<0.01)$.

Tab. 2. Serum phosphorus, chromium, copper and iron levels in study groups (mg/L).

\begin{tabular}{lcccc}
\hline Groups $(\mathrm{n}=10)$ & Phosphorus & Chromium & Copper & Iron \\
\hline 1-Control & $270.80 \pm 20.22 \mathrm{~A}$ & $0.08 \pm 0.05 \mathrm{~A}$ & $2.91 \pm 0.55 \mathrm{~A}$ & $3.65 \pm 0.65 \mathrm{~A}$ \\
2-Sham- hyperthyroidism & $274.76 \pm 22.50 \mathrm{~A}$ & $0.08 \pm 0.05 \mathrm{~A}$ & $3.01 \pm 0.75 \mathrm{~A}$ & $3.72 \pm 0.60 \mathrm{~A}$ \\
3- hyperthyroidism & $196.34 \pm 27.50 \mathrm{~B}$ & $0.05 \pm 0.02 \mathrm{~B}$ & $2.25 \pm 0.27 \mathrm{~B}$ & $2.17 \pm 0.40 \mathrm{~B}$ \\
\hline
\end{tabular}

*The difference between means with different superscripted letters in the same column is statistically significant $(\mathrm{p}<0.01)$. 
literature data quoted above. An important finding that should be noted herein is that alongside the selenium levels, the zinc levels were also elevated in the hyperthyroid group. It can be argued that both of these elements being known for their importance in thyroid metabolism should be studied further in order to shed light on their mutual interactions, as well as on their interactions with thyroid activity $(5,22)$.

By comparing the calcium levels between groups it was revealed that the hyperthyroidism group had higher calcium levels than the other two. It was stated in a study by Simsek et al (9) that erythrocyte calcium content in hyperthyroidism declined significantly, while a similar study showed that hyperthyroidism did not bring about any significant change in serum calcium levels (24). Hyperthyroidism is characterized by increased bone cycle due to direct stimulation of bone cells by elevated thyroid hormones (25). In case of excessive thyroid hormone secretion, the resorption increases faster than formation, and consequently, the serum calcium increases (26). The elevated serum calcium we found in the hyperthyroidism group may look like an expected result, and indeed, it is in harmony with the reports cited above $(25,26)$. However, the elevated calcium levels in the hyperthyroidism group may also be associated with high zinc levels found in the same group. In their study, O'Dell et al (27) showed that zinc deficiency in the body resulted in inadequate calcium absorption. It was reported that 1,25 dihydroxycholecalciferol levels in circulation dropped in zinc deficiency or alternatively that zinc supplementation stimulated the synthesis of 1,25 dihydroxycholecalciferol (28). The high calcium levels we obtained in the hyperthyroidism group not only may be associated with increased thyroid activity, but also may result from the increase in zinc levels.

The number of studies into magnesium levels in hyperthyroidism is limited. It was demonstrated that thyroxin supplementation increased the magnesium levels in rat hepatic tissue while reducing those in the heart tissue (29). It was reported that magnesium levels in patients with thyroid cancer declined significantly after surgical operation (30), as well as that both erythrocyte and plasma magnesium levels in experimental hyperthyroidism were lower than those in controls (9). In our study, magnesium levels of the groups were not different. This result may be due to the duration and severity of the induced hyperthyroidism. The report by Gilro et al (31) that the severity of hyperthyroidism might contribute to a decrease in ionized magnesium concentrations is an important finding lending support to our premise.

The hyperthyroidism group in our study had lower levels of chromium, copper, iron and phosphorus relative to other groups. Changes in thyroid activity are known to influence the copper metabolism (32). It was claimed that thyroid cancer patients had higher blood copper concentrations (22), whereas in another study it was shown that while pre-operative serum copper levels of thyroid cancer patients were not different from those of the controls, they were significantly suppressed post-operatively (30). However, the thyroxin supplementation elevated the copper levels in the liver, while anti-thyroid drug administration resulted in a decreased copper concentration in the liver and increased copper concentration in the kidney (29). The reduced copper levels obtained in our study support the results of researchers who have argued that copper metabolism is affected by thyroid malfunctioning. New data from human and animal studies indicate that iron defect weakens the thyroid metabolism $(33,34,35)$. Serum zinc concentrations of patients with thyroid cancer were shown to be significantly inhibited post-operatively (30). Eflekhari et al (33) reported in their study that there was a negative correlation between thyroid hormones and serum iron, and that the reduced serum iron accompanied the elevated thyroid hormone levels. The reduced levels of serum iron obtained in the present study are congruous with the results of Eflekhari et al (33). We have found no results of other studies that could be possibly compared to the decreased chromium and phosphorus levels we obtained in the hyperthyroidism group (group 3) in our study. However, our findings suggest that these elements are at least affected by hyperthyroidism. The reduced levels of chromium, copper, iron and phosphorus we found in the hyperthyroidism group may be associated with increased zinc levels. McDonal and Keen (36) point to an interaction between dietary zinc and other elements, arguing that high zinc can especially inhibit the iron absorption. The findings of our study indicate that there is an inverse relation between zinc and iron in particular. It has been noted that there is a balance between zinc, a trace element, and copper, iron and phosphorus $(37,38,39)$. It was reported that high doses of zinc could impair the copper-iron absorption (39), as well as that high doses of phosphorus-ironcopper could impair the zinc absorption $(40,41)$. The decrease in copper, iron and phosphorus values we obtained in our study may have resulted from increased zinc levels.

\section{Conclusions}

Results obtained in our study suggest that hyperthyroidism leads to changes in the levels of some elements in rats. These changes may be associated with elevated zinc levels in hyperthyroidism.

\section{References}

1. Ravaglia G, Forti P, Maioli F, Nesi B, Pratelli L, Savarino L, Cucinotta D, Cavalli G. Blood micronutrient and thyroid hormone concentrations in the oldest-old. J Clin Endocrinol Metab 2000; 85: 2260-2265.

2. Arthur JR, Beckett GJ. Thyroid function. Br Med Bull 1999; 55: 658-668.

3. Farooqi L, Mazeto GM, Shuhama T, Brandão-Neto J. Effects of a single venous dose of zinc on thyroid status in healthy individuals and patients with graves' disease. Met Based Drugs 2000; 7: 151-155.

4. Ganapathy S, Volpe SL. Zinc, exercise, and thyroid hormone function. Crit Rev Food Sci Nutr 1999; 39: 369-930.

5. Kralik A, Eder K, Kirchgessner M. Influence of zinc and selenium deficiency on parameters relating to thyroid hormone metabolism. Horm Metab Res 1996; 28: 223-226.

6. Morley JE, Russell RM, Reed A, Carney EA, Hershman JM. The interrelationship of thyroid hormones with vitamin A and zinc nutritional status in patients with chronic hepatic and gastrointestinal disorders. Am J Clin Nutr 1981; 34: 1489-1495. 
7. Yoshida K, Kiso Y, Watanabe TK, Kaise K, Kaise N, Itagaki Y, Yamamoto M, Sakurada T, Yoshinaga K. Erythrocyte zinc in hyperthyroidism: reflection of integrated thyroid hormone levels over the previous few months. Metabolism 1990; 39: 182-186.

8. Dursun N, Karatoy M, Akar S, Biberoğlu G. The influence of hyperthyroidism on zinc distribution in adult rats. Jpn J Physiol 1995; 45: 197-202.

9. Simsek G, Andican G, Unal E, Hatemi H, Yigit G, Candan G. Calcium, magnesium, and zinc status in experimental hyperthyroidism. Biol Trace Elem Res 1997; 57: 131-137.

10. LeBlondel G, Allain P. Effects of thyroparathyroidectomy and of thyroxin and calcitonin on the tissue distribution of twelve elements in the rat. Biol Trace Elem Res 1989; 19: 171-183.

11. Leblondel G, Le Bouil A, Allain P. Influence of thyroparathyroidectomy and thyroxine replacement on $\mathrm{Cu}$ and $\mathrm{Zn}$ cellular distribution and on the metallothionein level and induction in rats. Biol Trace Elem Res 1992; 32: 281-288.

12. Gupta RP, Verma PC, Garg SL. Effect of experimental zinc deficiency on thyroid gland in guinea-pigs. Ann Nutr Metab 1997; 41: 376-381.

13. Sandstead HH, Prasad AS, Schulert AR, Farid Z, Miale A Jr, Bassilly S, Darby WJ. Human zinc deficiency, endocrine manifestations and response to treatment. Am J Clin Nutr 1967; 20: 422-442.

14. Danforth E Jr, Burger AG. The impact of nutrition on thyroid hormone physiology and action. Annu Rev Nutr 1989; 9: 201-227.

15. Brandao-Neto J, Saturnino ACRD, Leite LD, Rocha EDD, Marcos CMP, da Silva CAB, Marchini JS, de Rezende AA, Grac M, Almeida A, Medeiros AC. Lack of acute zinc effect on thyrotropin-releasing hormone-stimulated thyroid-stimulating hormone secretion during oral zinc tolerance test in healthy men. Nutr Res 2006; 26: 493-496.

16. Pekary AE, Lukaski HC, Mena I, Hershman JM. Processing of TRH precursor peptides in rat brain and pituitary is zinc dependent. Peptides 1991; 12: 1025-1032.

17. Pawan K, Neeraj S, Sandeep K, Kanta Ratho R, Rajendra P. Upregulation of Slc39a10 gene expression in response to thyroid hormones in intestine and kidney. Biochim Biophys Acta 2007; 1769: 117-123.

18. Arthur JR, Nicol F, Becket GT. Selenium deficiency, thyroid hormone metabolism and thyroid hormone deiodinases. Am J Clin Nutr 1993; 57: 5236-5239.

19. Olivieri O, Girrelli D, Azzini M. Low selenium status in the elderly influences thyroid hormones. Clin Sci 1995; 89: 637-642.

20. Liu N, Liu P, Xu Q, Zhu L, Zhao Z, Wang Z, Li Y, Feng W, Zhu L. Elements in erythrocytes of population with different thyroid hormone status. Biol Trace Elem Res 2001; 84: 37-43.

21. Kvícala J, Zamrazil V. Effect of iodine and selenium upon thyroid function. Cent Eur J Public Health 2003; 11: 107-113.

22. Kucharzewski M, Braziewicz J, Majewska U, Gozdz S. Copper, zinc, and selenium in whole blood and thyroid tissue of people with various thyroid diseases. Biol Trace Elem Res 2003; 93: 9-18.

23. Dejneka W, Sworczak K, Obołończak L, Lukasiak J. Classification of thyroid gland disease on the basis of selenium concentration in serum. Rocz Panstw Zakl Hig 2007; 58: 563-567.
24. Simsek G, Karter Y, Aydin S, Uzun H. Osteoporotic cytokines and bone metabolism on rats with induced hyperthyroidism; changes as a result of reversal to euthyroidism. Chin J Physiol 2003; 46: 181-186.

25. Barsal G, Taneli F, Atay A, Hekimsoy Z, Erciyas F. Serum osteocalcin levels in hyperthyroidism before and after antithyroid therapy. Tohoku J Exp Med 2004; 203: 183-188.

26. Kir Z. The effects of thyroid gland on calcium and bone mineral metabolism. Turkish Journal of Medical Sciences 1995; 15: 148-155.

27. O'Dell BL, Emery M, Xia J, Browning JD. In vitro addition of glutathione to blood from zinc-deficient rats corrects platelet defects: impaired aggregation and calcium uptake. J Nutr Biochem 1997; 8: 346-350.

28. Kimmel PL, Watkins DW, Gubish CT, Slatopolsky E, Langman CB. Zinc nutritional status modulates the 1,25-(OH)2D. Response in uremic rats. Miner Electrolyte Metab 1991; 17: 307-314.

29. Al-Khayat TM, Al-Darweesh TM, Islam MS. The effect of thyroxine, the antithyroid drug propylthiouracil and thyroidectomy on mineral metabolism in rat tissues. J Clin Chem Clin Biochem 1982; 20: 281-285.

30. Al-Sayer H, Mathew TC, Asfar S, Khourshed M, Al-Bader A, Behbehani A, Dashti H. Serum changes in trace elements during thyroid cancers. Mol Cell Biochem 2004; 260: 1-5.

31. Gilroy CV, Horney BS, Burton SA, MacKenzie AL. Evaluation of ionized and total serum magnesium concentrations in hyperthyroid cats. Can J Vet Res 2006; 70: 137-142.

32. Zhang F, Liu N, Wang X, Zhu L, Chai Z. Study of trace elements in blood of thyroid disorder subjects before and after 131I therapy. Biol Trace Elem Res 2004; 97: 125-134.

33. Eftekhari MH, Keshavarz SA, Jalali M, Elguero E, Eshraghian MR, Simondon KB. The relationship between iron status and thyroid hormone concentration in iron-deficient adolescent Iranian girls. Asia Pac J Clin Nutr 2006; 15: 50-55.

34. Kubota K, Tamura J, Kurabayashi H, Shirakura T, Kobayashi I. Evaluation of increased serum ferritin levels in patients with hyperthyroidism. Clin Investig 1993; 72: 26-29.

35. Seymen HO, Civelek S, Seven A, Yigit G, Hatemi H, Burcak G. Iron supplementation in experimental hyperthyroidism: effects on oxidative stress in skeletal muscle tissue. Yonsei Med J 2004; 45: 413-418.

36. McDonald R, Keen CL. Iron, zinc and magnesium nutrition and athletic performance. Sports Med 1988; 5: 171-184.

37. Cordova A, Navas FJ. Effect of training on zinc metabolism: changes in serum and sweat zinc concentrations in sportsmen. Ann Nutr Metab 1998; 42: 274-282.

38. Clarkson PM. Minerals: exercise performance and supplementation in athletes. J Sports Sci 1991; 9: 91-116.

39. Haymes EM. Vitamin and mineral supplementation to athletes. Int $\mathrm{J}$ Sport Nutr 1991; 1: 146-169.

40. Fischer PW, Giroux A, L'Abbe MR. Effect of zinc supplementation on copper status in adult man. Am J Clin Nutr 1984; 40: 743-746.

41. Lukaski HC. Effects of exercise training on human copper and zinc nutriture. Adv Exp Med Biol 1989; 258: 163-170.

Received February 27, 2012. Accepted March 13, 2012. 